\title{
Characterization of $\beta$-Ti Alloy Prepared by SLM Method
}

Ilona Vonavkova ${ }^{1}$, Dalibor Vojtech ${ }^{1}$, David Palousek ${ }^{2}$

${ }^{1}$ Department of Metals and Corrosion Engineering, University of Chemistry and Technology in Prague. Technicka 5, 16628 Praha 6 - Dejvice. Czech Republic. E-mail: ilona.vonavkova@vscht.cz

${ }^{2}$ Department of Reverse Engineering and Additive Technologies, Brno University of Technology, Antoninska 548/1, 60190 Brno, Czech Republic. E-mail: palousek@fme.vutbr.cz

Ti-6Al-4V alloy is the most commercially used material for the production of orthopedic implants. However, despite its excellent properties, it is not an ideal material for use in medicine in terms of vanadium toxicity and relatively high modulus of elasticity. Titanium $\beta$-alloys could be a suitable replacement in future years for Ti-6Al-4V alloy, as they have a lower modulus of elasticity and contain non-toxic elements. Some of the alloying elements may even increase the biocompatibility of the alloy. In addition, a progressive 3D printing method would allow custom-made implants with the required properties to be printed. The aim of this work was to characterize the $\beta$ alloy Ti-30Nb by Selective Laser Melting (SLM) method and to determine its mechanical properties. In addition, heat treatment was applied in order to homogenize the structure. Ti-30 Nb alloy was compared in as-built state and in annealed state.

Keywords: Titanium alloy, Ti-Nb, 3D printing, SLM

\section{Introduction}

Titanium alloys are used in many engineering fields such as aerospace, marine and chemical industry and medicine $[1,2]$. They are used as permanent implants in orthopedic and dental applications due to their high strength, excellent corrosion resistance and good biocompatibility [3-5]. The most frequently used titanium alloy is Ti-6Al-4V. However, despite its good properties, there are some problems with long-term implantation [5]. First, Ti-6Al-4V alloy possess relatively high modulus of elasticity (about $110 \mathrm{GPa}$ ) [6]. Modulus of elasticity of cortical bone is approximately $30 \mathrm{GPa}$ [6]. This difference between the modulus of elasticity causes that bone is not sufficiently loaded and thinens. This is also known as stress shielding effect and can result in implant failure or even loosening of the implant $[3,7,8]$. Another problem is toxicity of vanadium $[4,5,9]$. Vanadium is considered as toxic and allergenic in its ionic form $\left(\mathrm{V}^{5+}\right)$ and in the form of oxide $\left(\mathrm{V}_{2} \mathrm{O}_{5}\right)$ [10]. To reduce these risks, in the last few years $\beta$-titanium alloys have been developed. Elements stabilizing $\beta$ modification are chosen as alloying elements, such as $\mathrm{Nb}, \mathrm{Mo}, \mathrm{Ta}$, $\mathrm{Mn}$ etc, and they are non-toxic. Titanium naturally occurs in two allotropic modifications. Low temperature modification is $\alpha$, with a hexagonal closepacked structure (hcp), and high temperature modification $\beta$ with a cubic body-centered structure (bcc). $\beta$ modification has a lower density of the arrangement of atoms and possesses lower modulus of elasticity [3]. High temperature $\beta$ modification can be stabilized up to room temperature by alloying titanium with suitable elements $(\mathrm{Nb}, \mathrm{Mo}, \mathrm{Ta})$. These alloying elements dissolve in titanium almost indefinitely and form a substitute solid solution. Due to this, $\beta$-Ti alloys are strengthened without significant decrease in mechanical properties. As a result, the alloys retain high strength and have a lower modulus of elasticity [11]. Furthermore, niobium helps to improve corrosion resistence [3] and biocompatibility $[3,10]$ of the alloy.

3D printing, also known as additive manufacturing, seems to be a promising technology for production of titanium alloys, especially in medicine. It allows to prepare complex structures with favorable properties that would not be possible to produce with conventional methods in almost onestep process from elemental powders mixture $[4,12]$. In general, 3D printing refers to a technology that creates a three-dimensional product layer by layer [12]. One of these technologies is the Selective Laser Melting (SLM) method. In the field of medicine, it would be possible to print custom-made implants [7, 12]. The resulting 3D product is gradually formed from a set of two-dimensional PC data (computeraided design - CAD or computed tomography - CT) $[7,13]$. The inicial material is a metal powder, which is gradually applied to the building platform by a feeder. On the building platform, the laser beam scans the powder bed, where the product is formed. Due to the high energy density of the laser, the material is completely melted during the process. After the layer is formed, the building platform is lowered by exactly the thickness of one layer and a new powder is loaded from the storage chamber with an arm. The process is 
repeated until the whole product is fabricated [14-16]. Furthermore, rapid heating and cooling of powder bed results in forming finer grains of alloy which is not achiavable by conventional methods (casting, forging etc.) [12]. Finer microstructure leads to higher mechanical properties, such as higher strength or higher yield stregth.

Nowadays, there are a few studies dealing with binary system $\mathrm{Ti}-\mathrm{Nb}$ prepared by Selective Laser Melting [3, 4, 12, 17]. Wang, J. C. et al. [3] prepared Ti$35 \mathrm{Nb}$ alloy by SLM method and compared as-SLMed sample with sample after heat treatment. Solution treatment was performed for $24 \mathrm{~h}$ at $1000{ }^{\circ} \mathrm{C}$ in order to homogenize the structure. Microstructure of Ti$35 \mathrm{Nb}$ alloy as-SLMed sample was highly heterogenous with undissolved $\mathrm{Nb}$ particles. After homogenization, yield stregth slightly decreased (from $660 \pm 13 \mathrm{MPa}$ to $640 \pm 12 \mathrm{MPa}$ ) but plasticity of the material increased. Some of the $\mathrm{Nb}$ particles still remained even after homogenization. The reason is that the diffusion coefficient of $\mathrm{Nb}$ into $\mathrm{Ti}$ is very low. Wang, Q. et al. [12] studied how $\mathrm{Nb}$ content influences the microstructure, the mechanical properties and the in vitro apatite-forming capability of Ti-xNb $(\mathrm{x}=15,25$ and 45 wt. \%) alloy prepared by SLM. The Ti-25Nb alloy achieved the lowest modulus of elasticity with relatively high ultimate tensile strength $(923 \pm 38$ $\mathrm{MPa})$ and yield stregth $(516 \pm 58 \mathrm{MPa})$. Fischer, M. et al. [4] prepared Ti-26Nb (at. \%) alloy by SLM process from mixed elemental powders. They compared the effect of laser energy density on the resulting porosity and homogenity of the structure. Structure of the alloy consisted of $\beta$ phase and undissolved $\mathrm{Nb}$ particles. It is obvious that the inhomogeneity of the material after printing is a major problem of binary $\mathrm{Ti}-\mathrm{Nb}$ alloys. This inhomogeneity can be reduced by optimizing the laser energy density or subsequent heat treatment.

\section{Materials and methods}

Mixture of elemental titanium and niobium powders were used for SLM process. Titanium particles were spherical, while niobium particles were irregular in shape (Fig. 1). The size distribution of the powder particles was measured by laser diffraction for particle size analysis with Fritsch Analysette 22 NanoTec. The size distribution of titanium particles was $\mathrm{D}_{10}=17.50 \mu \mathrm{m}, \mathrm{D}_{50}=35.77 \mu \mathrm{m}$ and $\mathrm{D}_{90}=60.79$ $\mu \mathrm{m}$ and niobium particles was $\mathrm{D}_{10}=9.12 \mu \mathrm{m}, \mathrm{D}_{50}=$ $25.21 \mu \mathrm{m}$ and $\mathrm{D}_{90}=49.55 \mu \mathrm{m}$. It is desirable for niobium particles to be smaller than titanium particles due to higher melting point of niobium $\left(2468{ }^{\circ} \mathrm{C}\right)$ compared to the melting point of titanium $\left(1668^{\circ} \mathrm{C}\right)$ [3]. Powders were mixed with weight proportion Ti: $\mathrm{Nb}=70: 30$. Then the mixture of powders was homogenized in Turbula for 30 minutes.
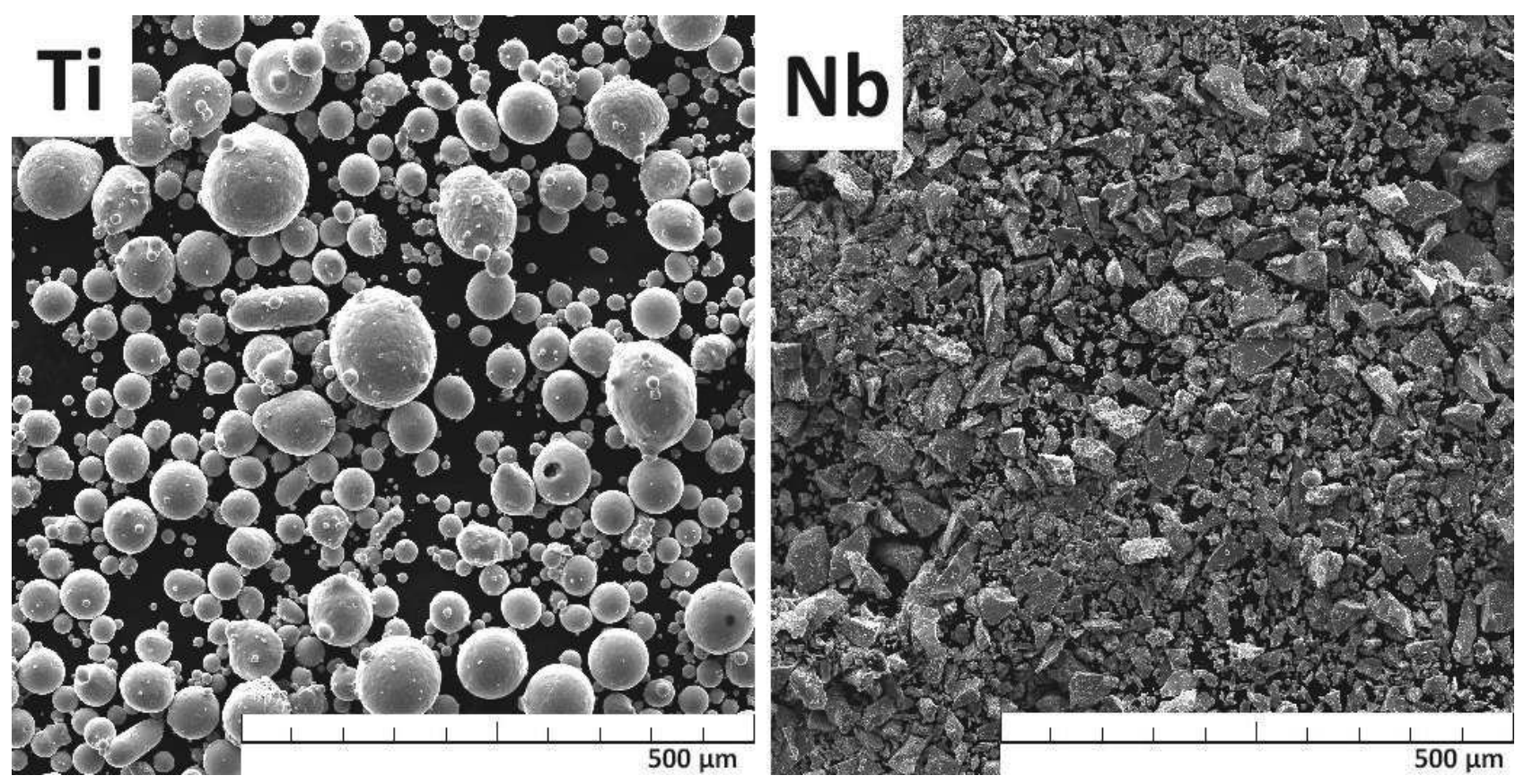

Fig. 1 Initial powders - titanium powder particles (left) and niobium powder particles (right).

Tab. 1 The SLM processing parameters.

\begin{tabular}{|c|c|c|c|c|c|}
\hline Sample & $\begin{array}{c}\text { Hatch distance } \\
{[\mathrm{mm}]}\end{array}$ & $\begin{array}{c}\text { Laser power } \\
{[\mathrm{W}]}\end{array}$ & $\begin{array}{c}\text { Laser speed } \\
{\left[\mathrm{mm} \cdot \mathrm{s}^{-1}\right]}\end{array}$ & $\begin{array}{c}\text { Layer } \\
\text { thickness } \\
{[\mathrm{mm}]}\end{array}$ & $\begin{array}{c}\text { Volume energy } \\
{\left[\cdot \mathrm{mm}^{-3}\right]}\end{array}$ \\
\hline 1 & 0.11 & 200 & 450 & 0.05 & 81 \\
\hline 2 & 0.11 & 200 & 500 & 0.05 & 73 \\
\hline
\end{tabular}


The Ti-30Nb alloy was prepared by SLM method (Selective Laser Melting) using SLM 280 HL machine equipped with and YLR fiber laser with maximum power of $400 \mathrm{~W}$. The printing was performed in an argon atmosphere to prevent oxidation of the final products. The SLM processing parameters are listed in Tab. 1. Printed samples were block shape with dimensions $10 \mathrm{~mm} \times 10 \mathrm{~mm} \times 4 \mathrm{~mm}(a \times b \times b)$.

The as-built samples were cut in direction pararrel to printing direction to study the microstructure. The samples were embedded in a potting compound, then ground on SiC abrasive papers P80-P2500 and then polished on diamond paste D2 followed by polishing on a 2:1 mixture of Eposil and hydrogen peroxide. Highlighting of the microstructure was achieved by etching the sample in Kroll's reagent consisting of 5 $\mathrm{ml} \mathrm{HNO}_{3}, 10 \mathrm{ml} \mathrm{HF}$ and $85 \mathrm{ml}$ distilled water. The microstructure was observed using an optical microscope (Olympus PME3) and scanning electron microscope (SEM - TescanVega3 LMU) equipped with an energy dispersive spectrometer (EDS, Oxford Instruments AZtec). Porosity was measured from microscope images by ImageJ software. Phase composition was characterized by X-ray diffraction with PANanalytical X'Pert PRO with a $\mathrm{Cu} \mathrm{K} \alpha$ source $(\lambda=0.1540 \mathrm{~nm})$.

Heat treatment was applied to homogenize the structure. The alloy was annealed at $1000^{\circ} \mathrm{C}$ for 24 $\mathrm{h}$ under vacuum.

Mechanical properties were determined from compression tests in the printing direction. Compression tests were carried out on universal testing machine LabTest 5.250SP1-VM. Samples had block shape with dimensions $\mathrm{a}=\mathrm{b}=3.5 \mathrm{~mm}$ and $\mathrm{h}=$ $4 \mathrm{~mm}$. The strain rate for the compression test was set at $0.001 \mathrm{~s}^{-1}$. Due to the lack of testing specimens, only one test was performed on each sample. The Vickers hardness was measured on the samples with a load of $1 \mathrm{~kg} .15$ measurements were made for each sample.

\section{Results and discussion}

\section{Microstructure}

Microstructure of SLM processed Ti-30Nb alloy was compared in as-built state and annealed state. Porosity of the as-built sample was $3.4 \pm 0.8 \%$ (Fig. 2 ). At first glance, it can be seen that the pores are formed mainly inside the melting pools (Fig. 3). During laser melting, due to high local temperatures, the material may evaporate and pores may form. Volume energy of laser was lower during printing second sample, which was annealed, due to higher laser speed. So, the porosity of the annealed sample decreased to $1.6 \pm 0.9 \%$ (Fig. 2). There was no excessive evaporation of material during laser beam melting and the quantity of pores decreased. Fig. 3 shows optical microscope images of Ti-30Nb alloy prepared by SLM process in as-built state. Melt pools are clearly visible as the sample was build layer by layer. Microstructure was consisted of $\beta$ grains and undissolved $\mathrm{Nb}$ particles.

The presence of undissolved $\mathrm{Nb}$ particles was also observed using a scanning electron microscope (Fig. 4). This can be caused by short interaction time during laser melting. First reason of this microstructure heterogenity could be significant difference between melting points of initial powders. $\mathrm{Nb}$ has high melting point of $2468{ }^{\circ} \mathrm{C}$ compared to $\mathrm{Ti}$, which is $1668^{\circ} \mathrm{C}$ [3]. Second reason could be difference between niobium particle size of initial powder. The interaction time was long enough to dissolve small particles but the larger ones remained undissolved.

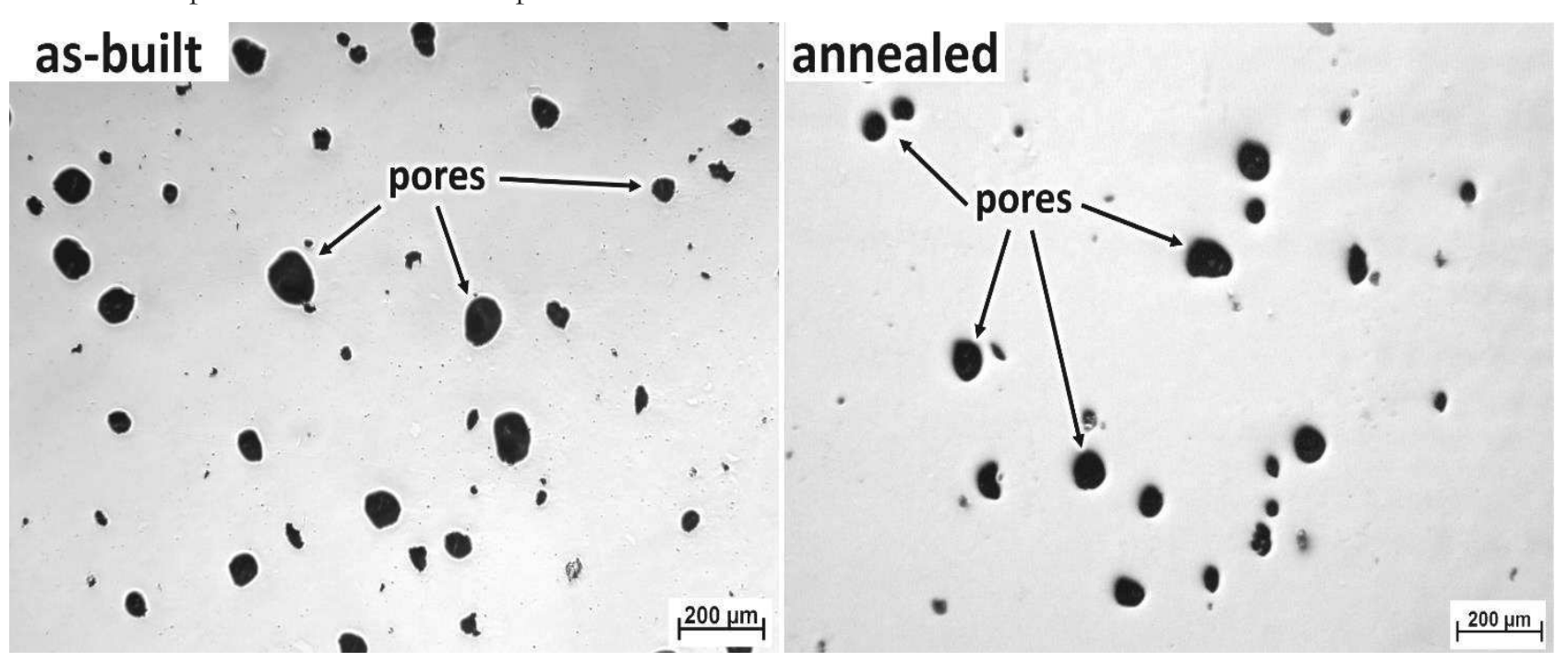

Fig. 2 Images for porosity evaluation of as-built sample (left) and annealed sample (right). 


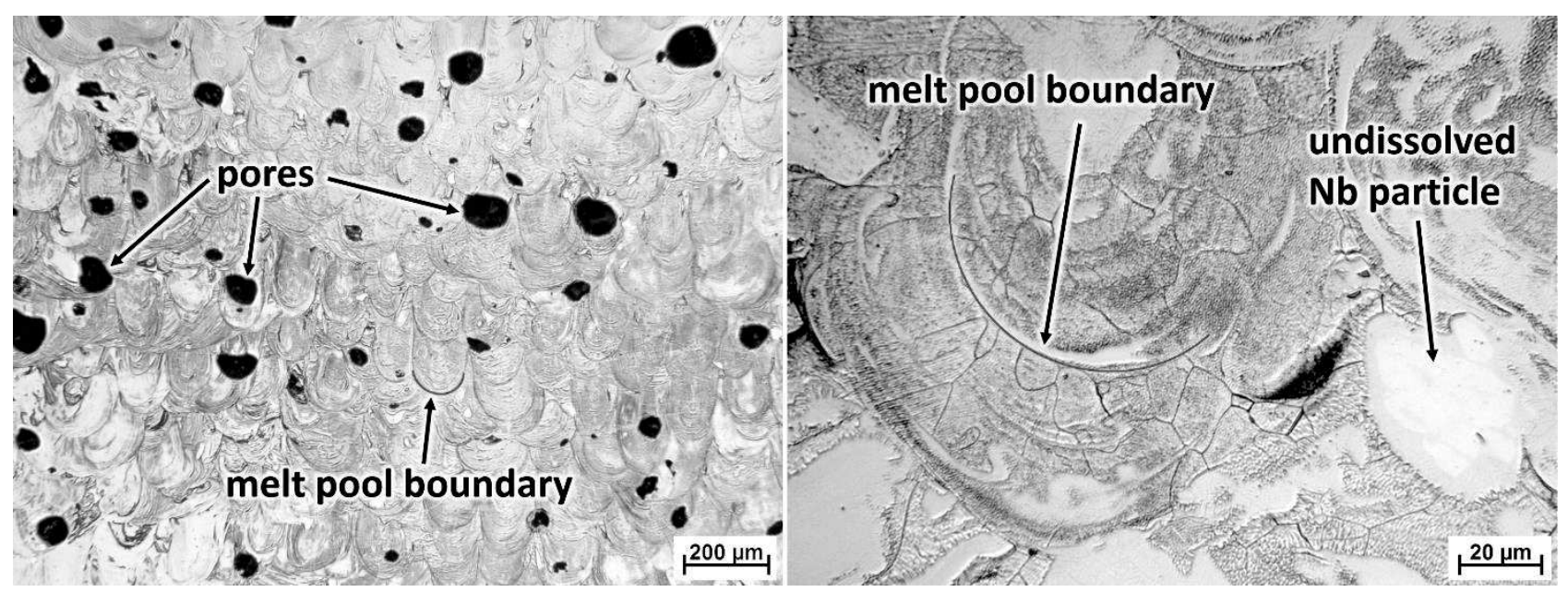

Fig. 3 Microstructure of the Ti-30Nb alloy prepared by SLM in as-built state (optical microscope).

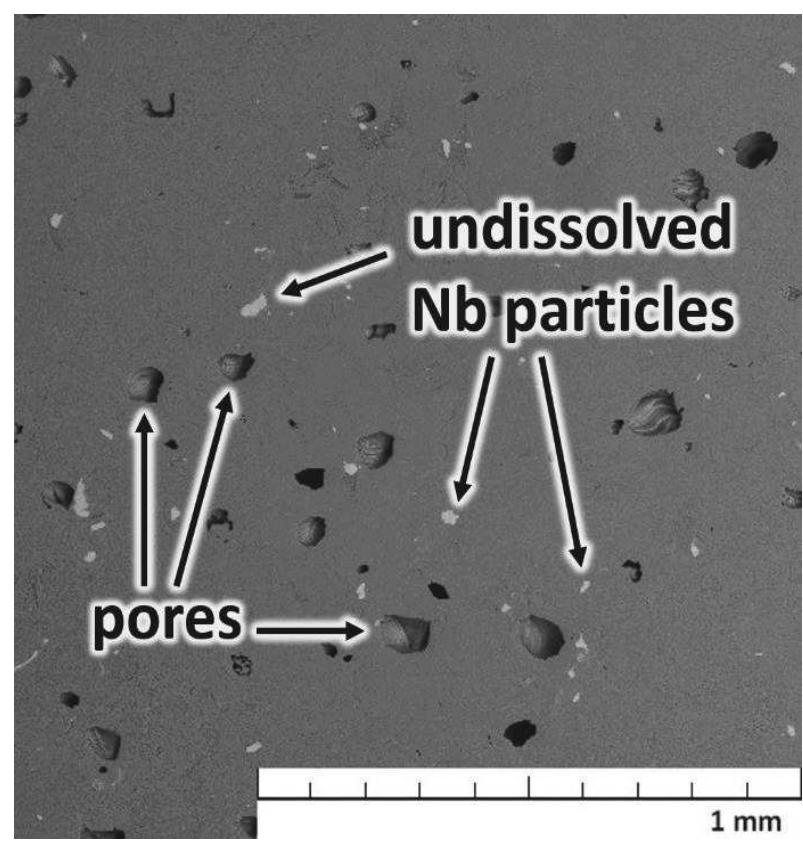

Fig. 4 Microstructure of the Ti-30Nb alloy prepared by SLM (SEM - BSE).

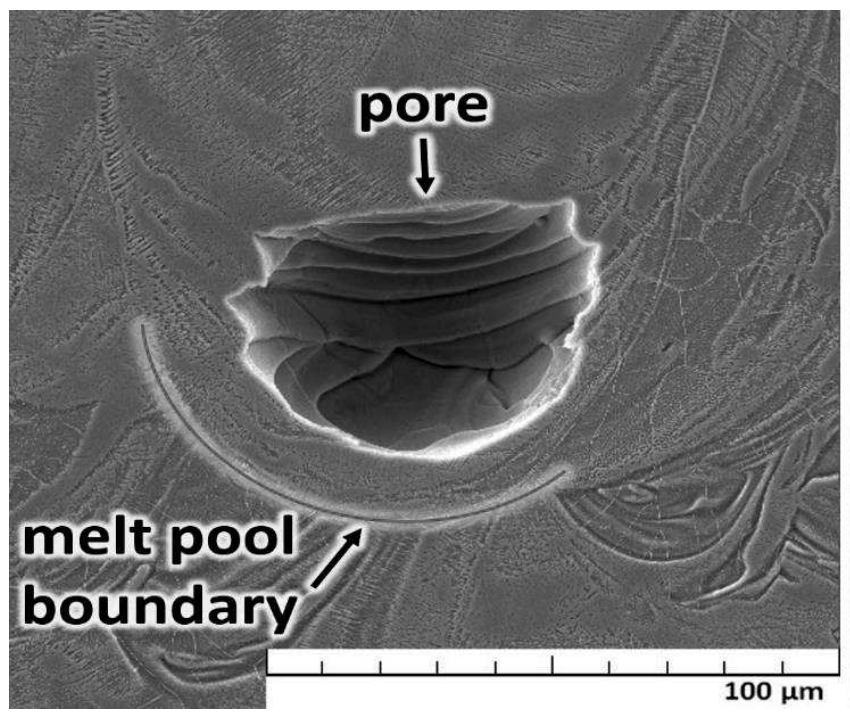

Presence of $\mathrm{Nb}$ undissolved particles was confirmed by EDS analysis. The layout of the individual elements is shown in Fig. 5. EDS point analysis revealed that the light grey particles ( $\mathrm{Nb}$ particles) in structure are composed of $99.5 \pm 0.5$ wt. $\% \mathrm{Nb}$ and $0.6 \pm 0.2$ wt. \% Ti. The composition of solid solution was 73.7 \pm 2.2 wt. Ti and $26.3 \pm 2.2$ wt. $\%$ Nb.

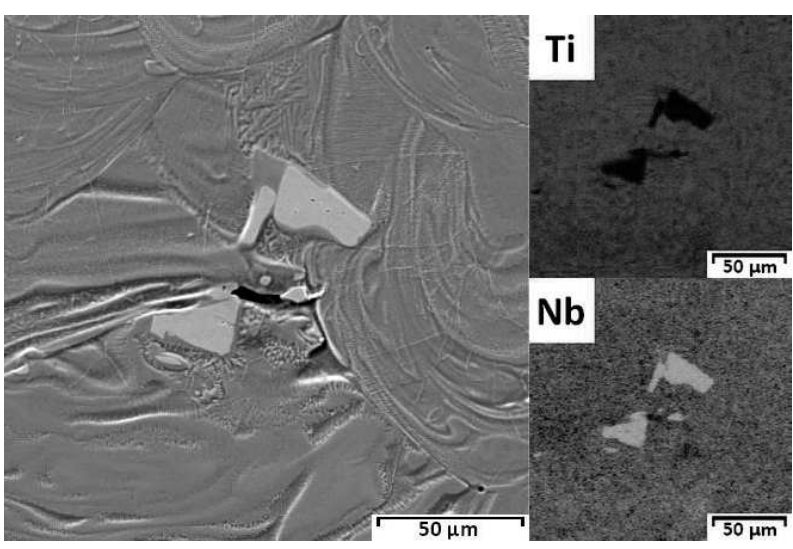

Fig. 5 EDS elemental mapping images - undissolved niobium particles (as-built sample).

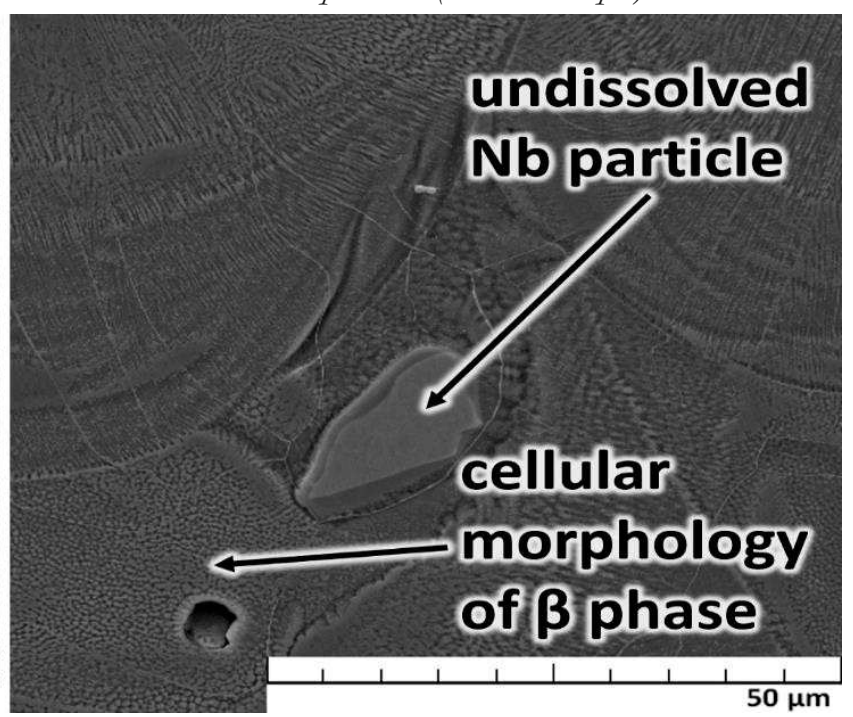

Fig. 6 Detailed image of microstructure of the Ti-30Nb alloy prepared by SLM in as-built state (SEM - SE). 
In Fig. 6, detailed image of pore and melt pool boundary is shown (left). Small $\beta$ grains in microstructure are also partially visible. More detailed image of microstructure is shown in Fig. 6 (right). A

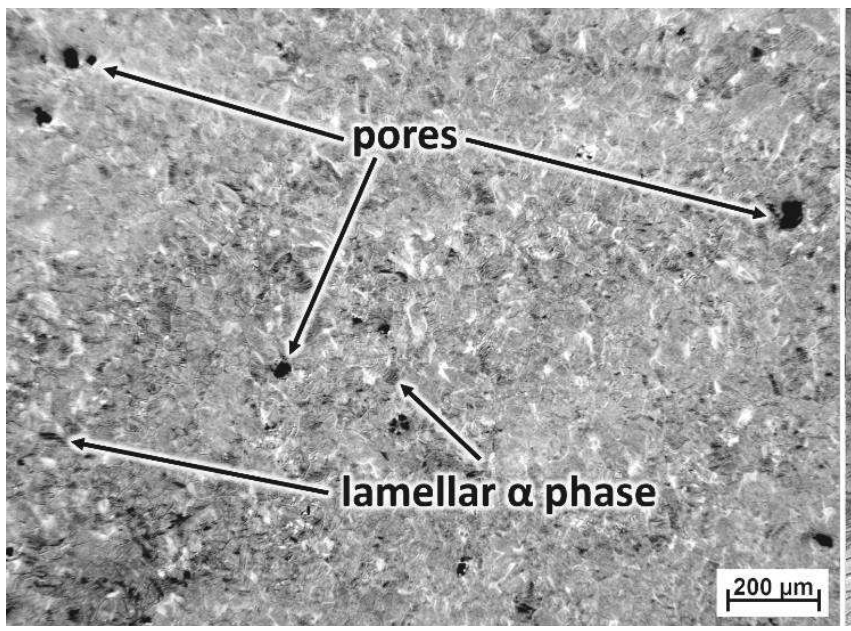

typicall cellular morphology of $\beta$ phase is visible. The same morphology was observed in study of Wang, Q. et al. [12].

Fig. 7 Microstructure of the Ti-30Nb alloy prepared by SLM in annealed state (optical microscope).

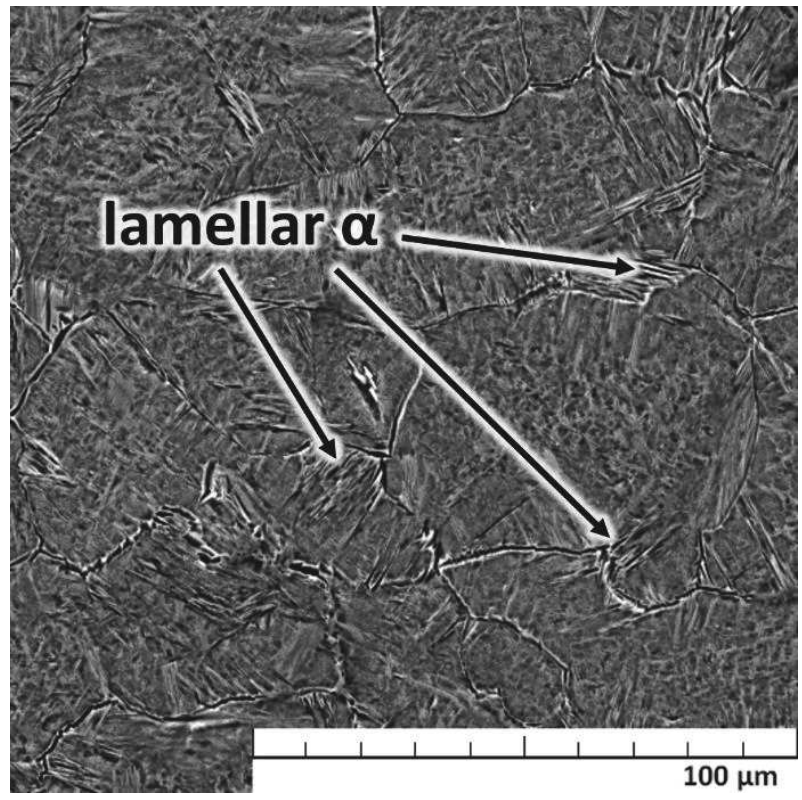

Fig. 8 Microstructure of the Ti-30Nb alloy prepared by $S L M$ in annealed state (SEM - SE).

Heat treatment was applied in order to homogenize the structure. Optical microscope images of microstructure of annealed sample are shown in Fig. 7. During annealing, $\mathrm{Nb}$ particles completely dissolved and the structure recrystallized. On the contrary, in the study Wang, J. C. et al. [3], they did not achieve dissolution of all remaining $\mathrm{Nb}$ particles after heat treatment. Particle size of initial Nb powder was higher $\left(\mathrm{D}_{50}=74.17 \mu \mathrm{m}\right)$ than in this study $\left(\mathrm{D}_{50}=25.21 \mu \mathrm{m}\right)$. Microstructure consisted of equiaxed $\beta$ grains and inside the grains lamellar $\alpha$ phase precipitated (Fig. 8). Presence of $\alpha$ phase in the structure was confirmed by XRD analysis (Fig. 9). The amount of $\alpha$ phase was approximately $20 \%$. After annealing the composition of solid solution was $60.9 \pm 1.1$ wt. $\%$ Ti and $39.1 \pm 1.5$ wt. $\% \mathrm{Nb}$. Niobium content in solid solution significantly increased, which correspods with dissolution of all niobium particles.

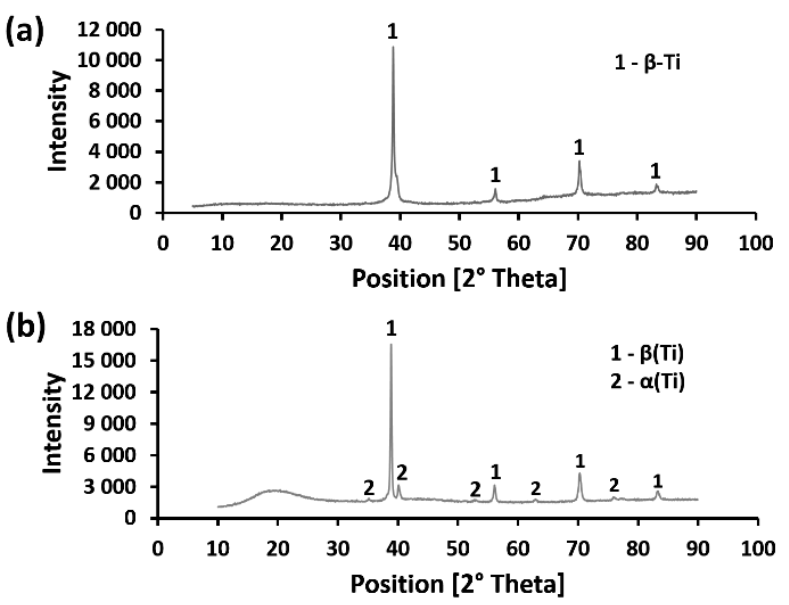

Fig. 9 Diffraction pattern of as-built (a) and annealed (b) sample.

\section{Mechanical properties}

Compression tests were performed in the printing direction. Both samples were relatively plastic. No material breakage occurred during the pressure test and the test was terminated. For this reason, no ultimate compressive strength or compressive strain of the material was determined. Dissolution of the niobium particles resulted in a solid solution stregthening and a slight increase in yield strength. Precipitation of $\alpha$ phase may also contribute to the higher yield strength. Compressive stress-strain curves are shown in Fig. 10.

On the contrary, Wang, J. C. et al. [3] achieved a slight decrease in yield strength and an increase in 
plasticity through heat treatment.

Vickers hardness with load of $1 \mathrm{~kg}$ was measured on both samples. The as-built sample reached a hardness of $318 \pm 13 \mathrm{HV} 1$. After heat treatment, the hardness slightly increased to the value of $326 \pm 7 \mathrm{HV}$ 1 , due to dissolution of the remaining $\mathrm{Nb}$ particles and solid solution stregthening.

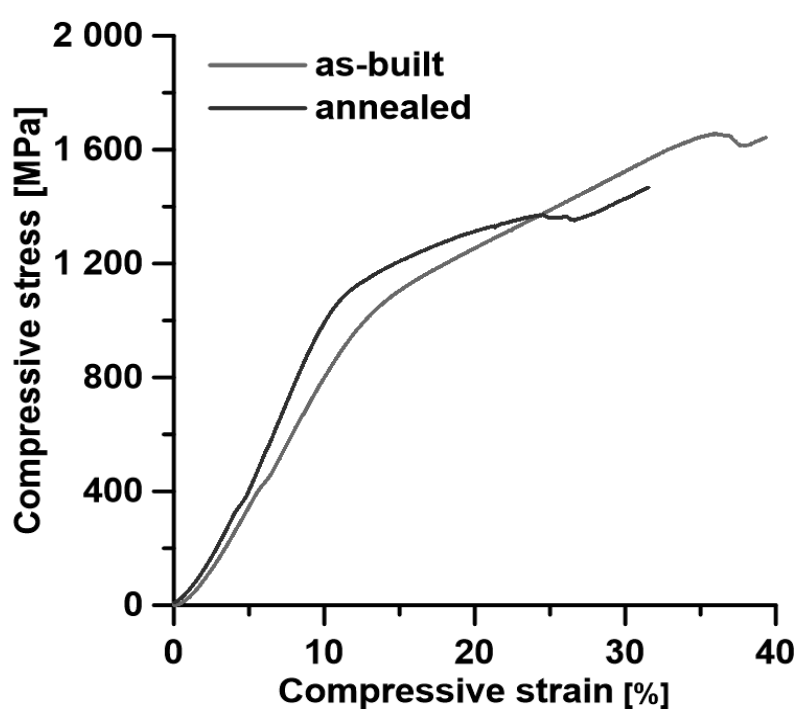

Fig. 10 Compressive stress-strain curves of as-built and annealed sample.

\section{Conclusion}

Binary $\beta$-Ti alloy $\mathrm{Ti}-30 \mathrm{Nb}$ was prepared by SLM method from mixture of elemental powders. Microstructure of the alloy in as-built state consisted of $\beta$-phase and undissolved niobium particles. Melt pool boundaries were clearly visible as the sample was formed layer by layer. The porosity of as-built sample was $3.4 \pm 0.8 \%$. In order to homogenize the structure, heat treatment was applied. Lamellar $\alpha$-phase precipitated during annealing. Microstructure after heat treatment was consisted of $\beta$-phase and $\alpha$-phase. Porosity of the annealed sample slightly decreased to $1.6 \pm 0.9 \%$, because of lower laser energy density. Both samples were relatively plastic, as there was no material breakage during the pressure tests. After annealing, yield stregth slightly increased from 894 $\mathrm{MPa}$ to $971 \mathrm{MPa}$ due to solid solution strengthening and precipitation of $\alpha$ phase. The same trend was observed in hardness.

These results show that it is necessary to perform heat treatment after $3 \mathrm{D}$ printing to achieve a homogeneous structure of the material. Annealing at temperature $1000{ }^{\circ} \mathrm{C}$ for 24 hours is sufficient for dissolution remaining $\mathrm{Nb}$ particles with respect to the particle size of the input powder. Niobium particles present in the initial powder should be smaller than titanium particles due to higher melting point and to the lower diffusion coefficinet of niobium.

\section{Acknowledgement}

This work was supported from the grant of Specific university research - grant No A1_FCHT_2020_003.

\section{References}

[1] NAGASE, T., et al., (2019), Additive manufacturing of dense components in beta-titanium alloys with crystallographic texture from a mixture of pure metallic element powders. Materials \& Design, Vol. 173,No., pp. 107771, 0264-1275.

[2] KOLLI, R. P.; DEVARAJ, A., (2018), A Review of Metastable Beta Titanium Alloys. Metals, Vol. 8,No., pp. 506,

[3] WANG, J. C., et al., (2019), Selective laser melting of $\mathrm{Ti}-35 \mathrm{Nb}$ composite from elemental powder mixture: Microstructure, mechanical behavior and corrosion behavior. Materials Science and Engineering: $A$, Vol. 760,No., pp. 214224, 0921-5093.

[4] FISCHER, M., et al., (2016), In situ elaboration of a binary Ti-26Nb alloy by selective laser melting of elemental titanium and niobium mixed powders. Materials Science and Engineering: $C, \mathrm{Vol}$. 62,No., pp. 852-859, 0928-4931.

[5] ZHOU, L., et al., (2019), Mechanical and corrosion behavior of titanium alloys additively manufactured by selective laser melting - A comparison between nearly $\beta$ titanium, $\alpha$ titanium and $\alpha+\beta$ titanium. Optics \& Laser Technology, Vol. 119,No., pp. 105625, 0030-3992.

[6] KAUR, M.; SINGH, K., (2019), Review on titanium and titanium based alloys as biomaterials for orthopaedic applications. Materials Science and Engineering: C, Vol. 102,No., pp. 844862, 0928-4931.

[7] ZHANG, L. C., et al., (2011), Manufacture by selective laser melting and mechanical behavior of a biomedical Ti-24Nb-4Zr-8Sn alloy. Scripta Materialia, Vol. 65,No. 1, pp. 21-24, 1359-6462.

[8] HYBASEK, V., et al., (2018), Effect of The Heat Treatment on The Bioactivity of Nanostructured Surfaces. Manufacturing Technology Journal, Vol. 18,No. 2, pp. 239-242, 12132489.

[9] ABDEL-HADY GEPREEL, M.; NIINOMI, M., (2013), Biocompatibility of Ti-alloys for long-term implantation. Journal of the Mechanical Behavior of Biomedical Materials, Vol. 20,No., pp. 407-415, 1751-6161. 
[10] EISENBARTH, E., et al., (2004), Biocompatibility of $\beta$-stabilizing elements of titanium alloys. Biomaterials, Vol. 25,No. 26, pp. 5705-5713, 0142-9612.

[11] WENG, W., et al., (2019), Effects of selected metallic and interstitial elements on the microstructure and mechanical properties of beta titanium alloys for orthopedic applications. Materialia, Vol. 6,No., pp. 100323, 2589-1529.

[12] WANG, Q., et al., (2017), Effect of Nb content on microstructure, property and in vitro apatite-forming capability of Ti-Nb alloys fabricated via selective laser melting. Materials \& Design, Vol. 126,No., pp. 268-277, 0264-1275.

[13] YAN, Q., et al., (2018), A Review of 3D Printing Technology for Medical Applications. Engineering, Vol. 4,No. 5, pp. 729-742, 2095-8099.
[14] NGO, T. D., et al., (2018), Additive manufacturing (3D printing): A review of materials, methods, applications and challenges. Composites Part B: Engineering, Vol. 143,No., pp. 172-196, 1359-8368.

[15] YAP, C. Y., et al., (2015), Review of selective laser melting: Materials and applications. Applied Physics Reviews, Vol. 2,No., pp. 041101,

[16] ROUDNICKA, M., et al., (2019), Differences in the Response of Additively Manufactured Titanium Alloy to Heat Treatment - Comparison between SLM and EBM. Manufacturing Technology Journal, Vol. 19,No. 4, pp. 668-673, 12132489.

[17] ZHURAVLEVA, K., et al., (2013), Production of Porous $\beta$-Type Ti-40Nb Alloy for Biomedical Applications: Comparison of Selective Laser Melting and Hot Pressing. Materials (Basel), Vol. 6,No. 12, pp. 5700-5712, 1996-1944. 